\title{
Extracellular sphingomyelinase activity impairs TNF-a-induced endothelial cell death via ADAM17 activation and TNF receptor 1 shedding
}

\author{
Anselm Sommer ${ }^{1}$, Marie Düppe ${ }^{1}$, Lena Baumecker ${ }^{1}$, Felix Kordowski ${ }^{1}$, Joscha \\ Büch $^{1}$, Johaiber Fuchslocher Chico ${ }^{2}$, Jürgen Fritsch ${ }^{2}$, Stefan Schütze ${ }^{2}$, Dieter \\ Adam $^{2}$, Maria Sperrhacke ${ }^{1}$, Sucharit Bhakdi ${ }^{1}$ and Karina Reiss ${ }^{1}$ \\ ${ }^{1}$ Department of Dermatology, University of Kiel, 24105 Kiel, Germany \\ ${ }^{2}$ Institute of Immunology, University of Kiel, 24105 Kiel, Germany \\ Correspondence to: Karina Reiss, email: kreiss@dermatology.uni-kiel.de \\ Keywords: sphingomyelinase, ADAM17, apoptosis, TNF- $a$, TNFR 1 \\ Received: February 28, $2017 \quad$ Accepted: July 11, $2017 \quad$ Published: August 07, 2017 \\ Copyright: Sommer et al. This is an open-access article distributed under the terms of the Creative Commons Attribution License \\ 3.0 (CC BY 3.0), which permits unrestricted use, distribution, and reproduction in any medium, provided the original author and \\ source are credited.
}

\section{ABSTRACT}

ADAM17, a prominent member of the "Disintegrin and Metalloproteinase" (ADAM) family, is an important regulator of endothelial cell proliferation and cell survival. The protease controls vital cellular functions through cleavage of growth factors, cytokines and their receptors including transforming growth factor-alpha (TGF-a), tumor necrosis factor-alpha (TNF-a) and TNF-a receptor 1 (TNFR1). TNF-a is the major inducer of endothelial cell death in cardiovascular diseases. The latter are also characterized by elevated plasma and tissue levels of extracellular sphingomyelinase (SMase). Whether the SMase affects ADAM activity and thus endothelial cell function has not been addressed to date. Here, we analyzed the effect of SMase on ADAM17mediated shedding in COS7 cells and in human umbilical vein endothelial cells (HUVECs). Exposure to SMase significantly increased ADAM17-mediated release of alkaline-phosphatase (AP)-tagged TGF-a in COS7 cells and shedding of endogenously expressed TNFR1 in HUVECs. We previously presented evidence that surface exposure of phosphatidylserine (PS) is pivotal for ADAM17 to exert sheddase function. We found that SMase treatment led to PS externalization in both cell types. Transient nonapoptotic PS exposure is often mediated by $\mathrm{Ca}^{2+}$-dependent phospholipid scramblases. Accordingly, the $\mathrm{Ca}^{2+}$-chelator EGTA markedly reduced the breakdown of phospholipid asymmetry and shedding of TGF-a and TNFR1. Moreover, sheddase activity was significantly diminished in the presence of the competing PS-headgroup OPLS. SMasestimulated TNFR1 shedding strikingly diminished TNF-a-induced signalling cascades and endothelial cell death. Taken together, our data suggest that SMase activity might act as protective factor for endothelial cells in cardiovascular diseases.

\section{INTRODUCTION}

The discovery of ceramide as a central player in the sphingolipid signaling network opened a new area in biology, providing links to fundamental events involved in cell death and differentiation, oncogenesis, and inflammation [1-4]. Ceramide generation occurs through cleavage of sphingomyelin, which is located mainly in the outer leaflet of the plasma membrane. This process can be mediated by sphingomyelinases (SMases), preferentially active at either acid (aSMase) or neutral (nSMase) $\mathrm{pH}$ [5]. Dependent on posttranslational modification, aSMase is trafficked either to the lysosome or secreted extracellularly. Elevated serum levels of soluble aSMase have been reported in pathological states including atherosclerosis, type II diabetes, sepsis, chronic 
heart failure, and hyercytokinemia [5]. In cell culture, aSMase is secreted by various cell types including human vascular endothelial cells [6]. However, hardly anything is known about the function of soluble aSMase in the extracellular environment, where neutral $\mathrm{pH}$ bars its activity [7]. Neutral sphingomyelinase (nSMase) is located intracellularly and thus does not reach its substrate in the unperturbed cell $[5,8]$.

Yet, ceramide generation by both aSMase and nSMase has been implicated as an important event occurring in apoptotic cells [5, 7, 9-13]. The relevance thereof is a subject of continuing research. Ceramide generation per se does not promote cell death, as has been demonstrated in experiments employing bacterial sphingomyelinase from Staphylococcus (S.) aureus that is active at neutral $\mathrm{pH}$. Application of the soluble enzyme at high concentrations that cause massive ceramide generation does not lead to death of resting lymphocytes, fibroblasts or endothelial cells $[14,15]$. The possibility that ceramide might subserve a hitherto undescribed function in the context of sphingolipidderived cell signaling events appears likely.

Published reports on the effects of ceramide on the organization of membrane lipids provided us with the decisive lead for the present work. Investigations conducted with erythrocytes and platelets disclosed that ceramide disrupts membrane phospholipid asymmetry, leading to exposure of phosphatidylserine (PS) at the external membrane face $[16,17]$. These seminal studies, which capitalized on the use of bacterial sphingomyelinase as the generator of ceramide, did not extend to nucleated cells. In the latter, we recently discerned that transient PS exposure occurred in response to diverse major signaling events including $\mathrm{Ca}^{2+}$-elevation, purinergic receptor activation, and protein kinase $\mathrm{C}$ activation [18, 19]. PS exposure appeared to be the decisive event leading to manifestation of the sheddase function of ADAM17, predominant member of the family of $\mathrm{Zn}^{2+}$-dependent transmembrane metalloproteinases. ADAM17 fulfills multifaceted, vital roles in cell biology by liberating functional proteins and peptides from their membrane anchors [20]. It cleaves both membrane-bound TNF- $\alpha$ and its receptor TNFR1 $[21,22]$, and is also the major sheddase involved in EGFRactivation through release of the ligands amphiregulin, epiregulin, TGF- $\alpha$ and HB-EGF [23]. Amongst its many other functions, ADAM17 is thus also a key player in events governing cell survival and proliferation.

Here, we report that sphingomyelinase treatment results in PS exposure in COS7 and human endothelial cells, and this is accompanied by shedding of ADAM17 substrates. Proteolysis was suppressed in the presence of soluble phosphorylserine but not phosphorylcholine, indicating a pivotal role of PS in triggering sheddase function. Release of TNFR1 from endothelial cells concomitantly reduced the apoptotic effects of TNF- $\alpha$ and thus appeared to exert a protective function. Transient breakdown of membrane phospholipid asymmetry could represent a key link between the sphingolipid signaling cascade and the ADAM regulatory network.

\section{RESULTS}

\section{Extracellular sphingomyelinase induces ADAM17-mediated TGF- $\alpha$-AP shedding in COS7 cells and TNFR1 shedding in primary endothelial cells}

ADAM17 is ubiquitously expressed in all cell types and plays various roles depending on the stimuli and available substrates. To discern whether extracellular sphingomyelinase would affect ADAM17-mediated shedding, COS7 cells were transfected with the AP-tagged ADAM17 substrate TGF- $\alpha$ and stimulated with $0.1 \mathrm{U} /$ $\mathrm{ml}$ SMase for 3 hours in the presence or absence of the preferential ADAM10 inhibitor GI254023X (GI) and the ADAM10 and -17 inhibitor GW280264 (GW) [24]. The AP-activity in the supernatant and the cell lysates was determined as readout for TGF- $\alpha$ shedding (Figure 1A). Extracellular SMase induced the release of soluble TGF- $\alpha$ AP in an ADAM17-dependent manner as indicated by the strong inhibitory effect of GW compared to GI.

Increased sphingomyelinase activity in inflammatory and infectious diseases is often observed in serum [7]. This raises the question whether endothelial cell function would be affected. Therefore, we analyzed the effect of soluble SMase on ADAM17-mediated shedding in primary human umbilical vein endothelial cells (HUVECs). These cells were treated with $0.1 \mathrm{U} / \mathrm{ml}$ SMase with or without GI or GW for 2 hours. The conditioned supernatant was then analyzed for the ADAM17 substrate TNFR1 by ELISA. Comparable to the results in COS7 cells, SMase significantly increased the release of TNFR1 into the supernatant. This was significantly inhibited by GW but not by GI (Figure 1B), indicating that ADAM17 is the responsible protease for SMase-induced TNFR1 shedding.

Regulation of ADAM17 function occurs at many levels. During ADAM17 maturation, the pro-domain is removed by pro-protein convertases [25]. Mature ADAM17 is trafficked to the cell surface to fulfill its function. To find out whether the effects of SMase on ADAM17 activation would include changes in protein expression or maturation, HUVECs were analyzed by immunoblot analysis. As shown in Figure 1C, there was no change in the total cellular amount of ADAM17 or in the maturation, clearly indicating that another mechanism must be responsible for the increased shedding capacity.

\section{Extracellular SMase induces phosphatidylserine exposure}

We recently presented evidence that a direct interaction of ADAM17 with externalized phosphatidylserine (PS) is required for the protease to exert its sheddase function [18]. 

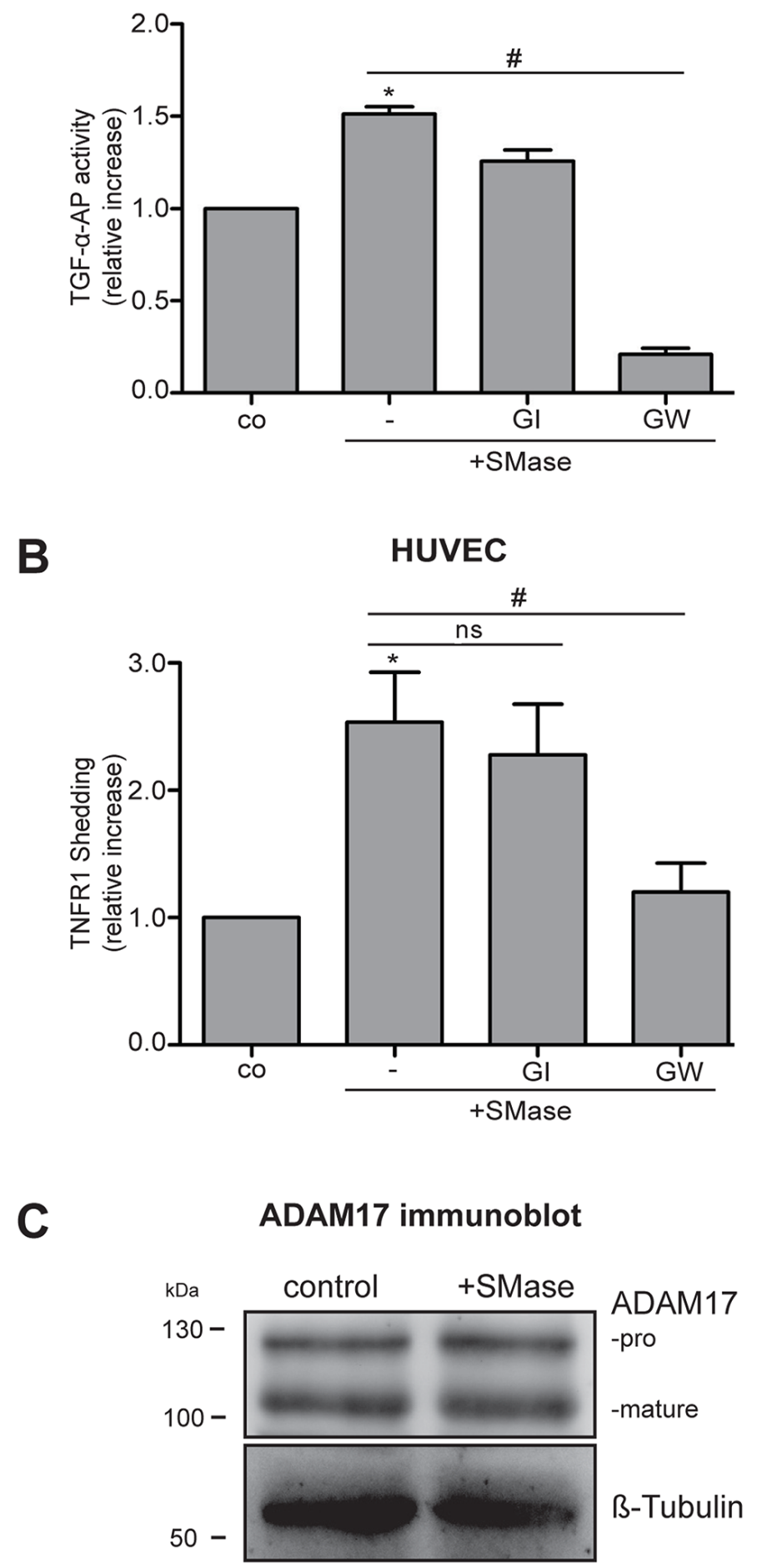

Figure 1: Extracellular SMase induces ADAM17-mediated shedding of TGF- $\alpha$-AP in COS7 cells and TNFR1 release in HUVECs. (A) Cells were stimulated with $0.1 \mathrm{U} / \mathrm{ml}$ SMase in the presence and absence of the ADAM10 inhibitor GI254023X (GI, $3 \mu \mathrm{M})$ or the ADAM17 and -10 inhibitor GW280264 (GW, $3 \mu \mathrm{M})$. The release of the transfected AP-tagged TGF- $\alpha$ was determined in COS7 cells upon $3 \mathrm{~h}$ of SMase treatment. (B) The release of the endogenous ADAM17 substrate TNFR1 in the supernatant was measured by ELISA in HUVECs after $2 \mathrm{~h}$ of SMase stimulation. Values are plotted as relative increase compared to control. * indicates a significant increase compared to control, \# indicates a significant reduction in comparison to the stimulated sample, ns: no significant differences $(* \#$ : $\mathrm{p}<0.05 ; \mathrm{n}=5$; $\pm \mathrm{SEM})$. (C) HUVECs were stimulated with SMase $(0.1 \mathrm{U} / \mathrm{ml})$ for $2 \mathrm{~h}$ and analyzed for ADAM17 expression by immunoblot analysis. No changes in the amount of mature or pro-ADAM17 were observed. $\beta$-Tubulin was used as loading control. 
PS exposure is known to be induced by sphingomyelinasedependent formation of ceramide [26]. Exposure to bacterial SMase was found to significantly augment phosphatidylserine exposure in erythrocytes and platelets [16, 17].

Whether HUVECs would respond in a similar way was addressed in the next experiment. HUVECs were stained with the fluorescently labeled PS probe Annexin V at different time points during SMase stimulation (Figure 2A). PS externalization became detectable upon $30 \mathrm{~min}$ and increased over the whole stimulation period. The staining was punctured and did not affect the entire plasma membrane. Although less pronounced, PS externalization could also be observed in COS7 cells in a comparable manner (Figure 2B).

\section{Sphingomyelinase-induced ADAM17-mediated shedding involves PS externalization}

Calcium homeostasis plays a key role in the regulation of phospholipid asymmetry at the membrane by controlling the activity of scramblases and ATP-dependent flippases [27, 28].

Non-apoptotic, transient PS exposure is often mediated by $\mathrm{Ca}^{2+}$-dependent phospholipid scramblases including the transmembrane protein 16F (TMEM16F), also called Anoctamin-6 (ANO6) [29, 30]. ANO6 activity strongly depends on the presence of $\mathrm{Ca}^{2+}$ [29]. Based on this fact, we investigated whether $\mathrm{Ca}^{2+}$ might play a role in the SMase-induced PS scrambling. Indeed, the $\mathrm{Ca}^{2+}$-chelator EGTA markedly reduced phospholipid externalization in COS7 cells and in HUVECs (Figure 3A) at any time point without affecting the SMase activity itself (Figure 3B). To test whether this reduced PS exposure would be accompanied by reduced ADAM17 activity, both cell types were analyzed in parallel in shedding assays. Indeed, SMase-induced ADAM17-mediated shedding was significantly diminished upon EGTA treatment (Figure $3 \mathrm{C}$ and 3D). Control experiments using the classical ADAM17 activator phorbol-myristate-acetate (PMA), that also acts via PS exposure in keratinocytes [18], were performed (Supplementary Figure 1). Indeed, EGTA also reduced PMA-stimulated PS exposure and concomitantly shedding in COS7 cells. To exclude that EGTA just extracted $\mathrm{Zn}^{2+}$ that was required for ADAM activity cells were pre-incubated with EGTA and washed before PMA stimulation. No differences in shedding induction were observed, leading to the conclusion that EGTA does not affect the bona fide catalytic activity of ADAM17.

To directly probe the relevance of externalized PS, HUVECs were treated with SMase in the presence or absence of OPLS or OPC, the soluble head group of phosphatidylserine or phosphatidylcholine, respectively. Whereas OPC did not affect SMase-induced TNFR1 shedding, OPLS led to a substantial reduction of substrate release (Figure 3E).

\section{TNFR1 shedding in HUVECs decreases TNF- $\alpha$ sensitivity}

Binding of TNF- $\alpha$ to the TNFR1 on endothelial cells is followed by rapid activation of the transcription factor $\mathrm{NF}-\kappa \mathrm{B}$. Initiator caspases cleave effector caspases including caspase-3. Caspase activation leads to cleavage of poly(ADP-ribose) polymerase-1 (PARP-1) and to the characteristic membrane blebbing, DNA fragmentation and laddering associated with apoptotic death. To analyze the SMase effect on TNF- $\alpha$-induced cell death, HUVECs were pretreated with SMase following incubation with TNF- $\alpha$. The level of activated p65 NF- $\kappa$ B, cleaved caspase-3 (cl Casp3), and the generation of cleaved PARP-1 (cl PARP) were explored after 2 and 4 hours by immunoblot analysis. Despite equal protein loading, the amount of total PARP-1 protein showed some variability, that was, however, not significant (Supplementary Figure 2). The TNF- $\alpha$-induced increase of p65 NF- $\kappa \mathrm{B}, \mathrm{cl}$ caspase-3, and cl PARP was clearly visible after 4 hours (Figure 4A). Pre-incubation with SMase reduced the induction of the apoptotic cascade.

The protective effect of SMase on the apoptotic response was additionally measured by nuclear fragmentation analysis using ImageStream cytometry. As to be expected, HUVECs showed strong nuclear fragmentation after TNF- $\alpha$ exposure (Figure 4B). This effect was significantly reduced when cells were pretreated with SMase. To ensure that a direct link between SMase and ADAM17 activation exists, cells were pretreated with the GW inhibitor and analyzed for TNF- $\alpha$-induced cell death by immunoblot (Figure 4C). Indeed, inhibition of ADAM17 abrogated the protective SMase effect. Generation of cleaved PARP-1 and caspase- 3 was much stronger in the presence of GW compared to only TNF- $\alpha$ treated cells. The protective role of external SMase as well as the opposite effect of GW was also indicated by corresponding changes in the number of blebbing cells induced by TNF- $\alpha$ incubation (Figure 4D and Supplementary Figure 3). Overall, these results show that SMase-induced ADAM17 activation counteracts TNF- $\alpha$ induced cell death of endothelial cells.

\section{DISCUSSION}

SMases plays a central role in the production of ceramide, a bioactive molecule with contradictory properties. Ceramide generation by cellular SMases accompanies apoptosis, and a role for the molecule in the events leading to cell death is being discussed. On the other hand, generation of ceramide in the absence of concomitant triggering events is not cytotoxic. Thus, endothelial cells, fibroblasts and resting lymphocytes tolerate treatment with high doses of bacterial SMase with no loss of viability [31]. 
Further to its roles as a signaling molecule, ceramide affects the microarchitecture of cell membranes, directing lateral flow of lipids and proteins to orchestrate the function of signaling platforms and regulate membrane movement [7, 32-34]. In glial cells, ceramide may assume a prime function in promoting formation of microvesicles $[35,36]$, an aspect that deserves to be followed up in other cell systems including endothelial cells.
Moreover, ceramide generated in erythrocytes and platelets through treatment of cells with bacterial SMase provokes breakdown of membrane phospholipid asymmetry and exposure of PS at the external membrane face. We anticipated that the latter phenomenon would extend to nucleated cells, in which case a novel link could emerge between ceramide and the regulatory network of membrane-anchored sheddases. ADAM17, eminent

A

HUVEC
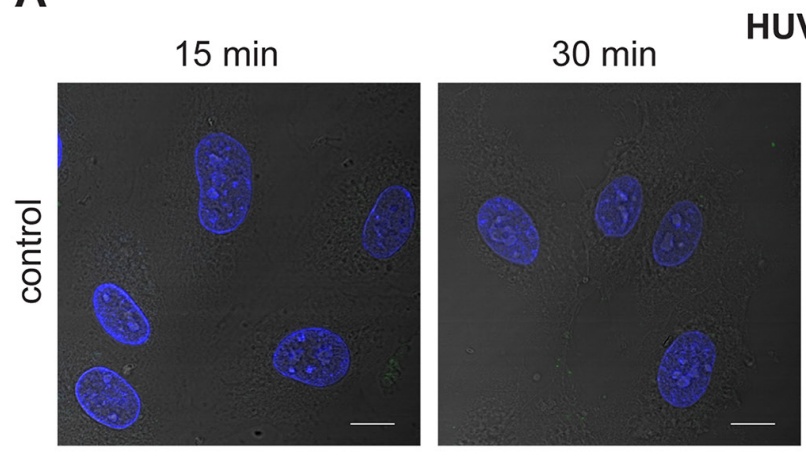

$60 \min$
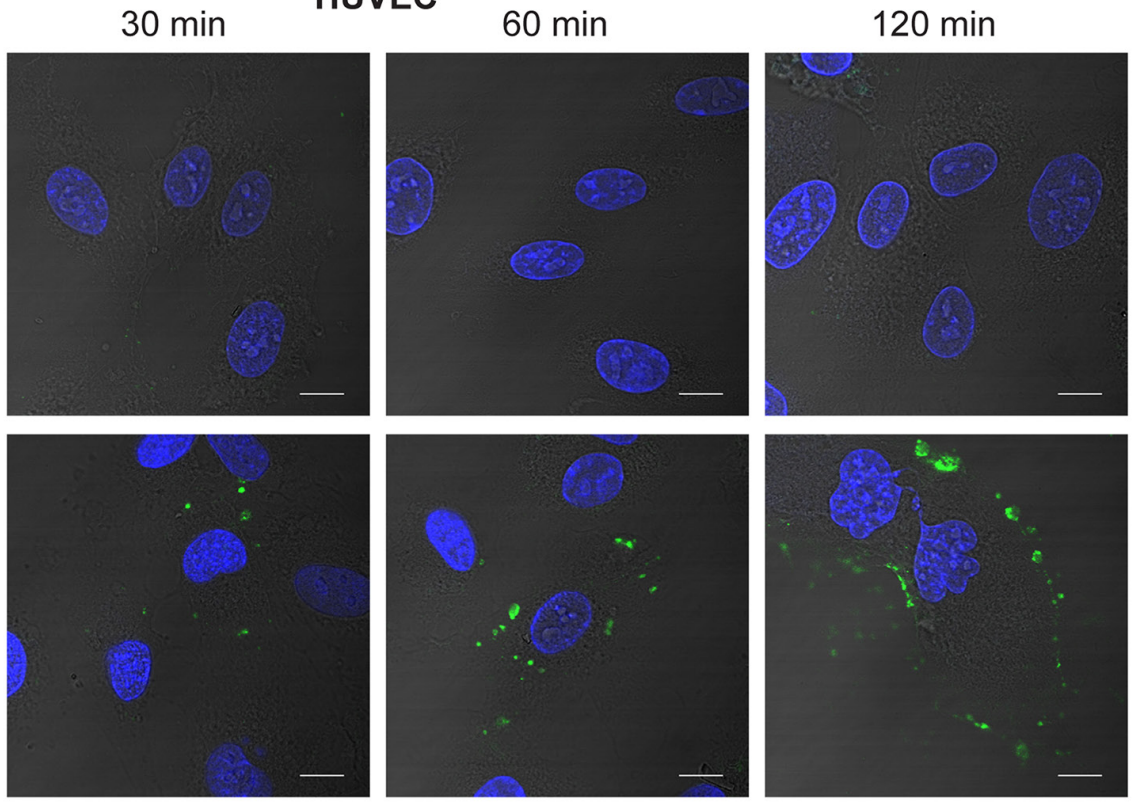

B
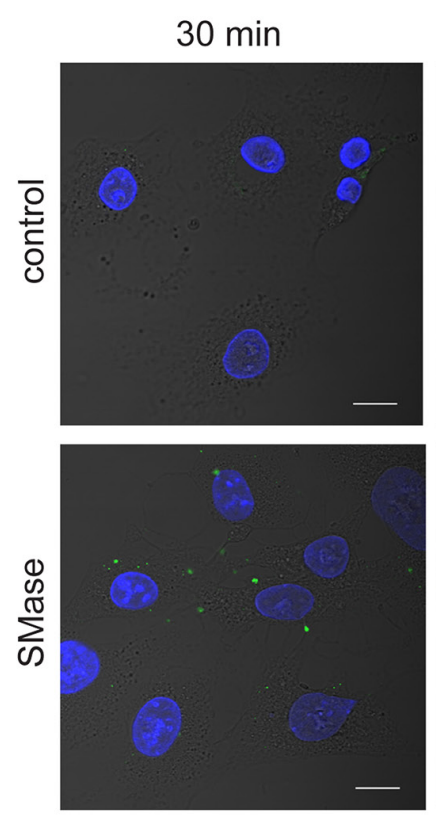

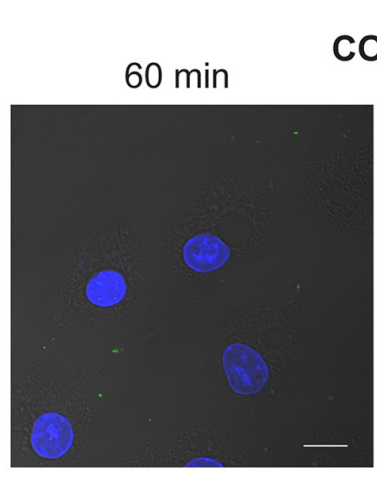

$\cos 7$
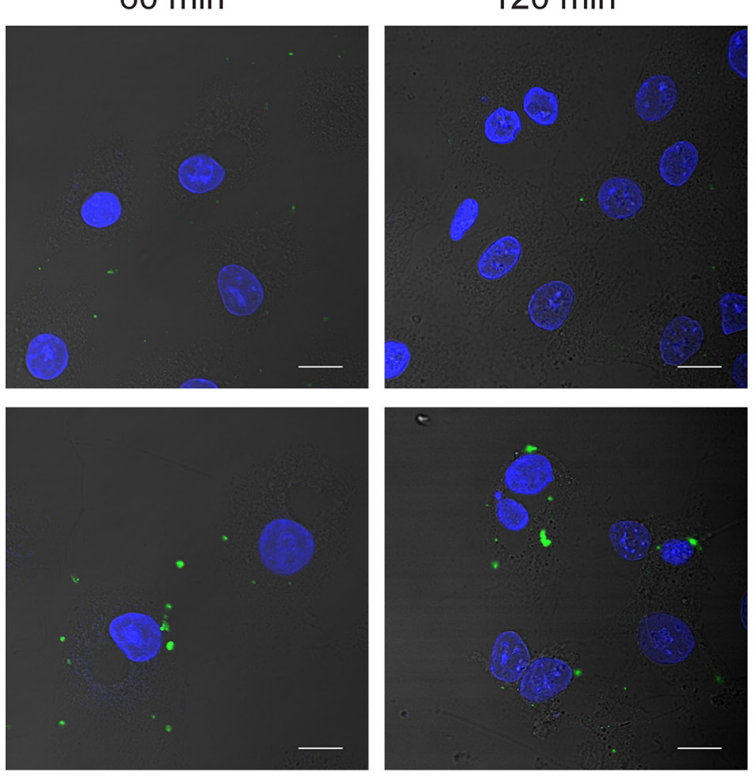
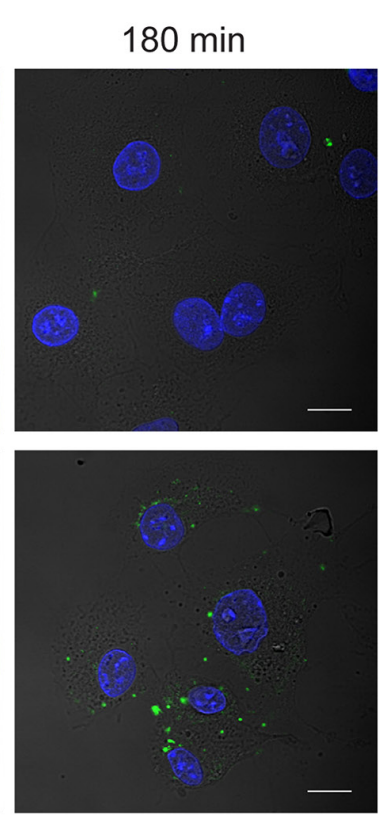

Figure 2: SMase stimulation induces phosphatidylserine exposure in HUVEC and COS7 cells. HUVEC (A) and COS7 cells (B) were treated with $0.1 \mathrm{U} / \mathrm{ml}$ SMase for the indicated time points and stained with Annexin V-FITC for detection of externalized PS (green) and DAPI for visualizing the nucleus (blue). Representative images of three independent experiments are shown. Scale bars, $10 \mu \mathrm{m}$. 
A

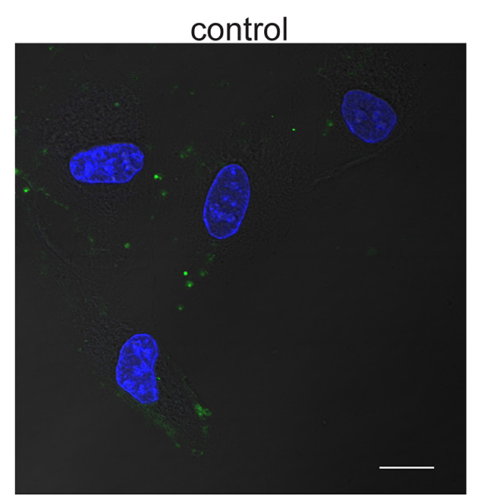

control

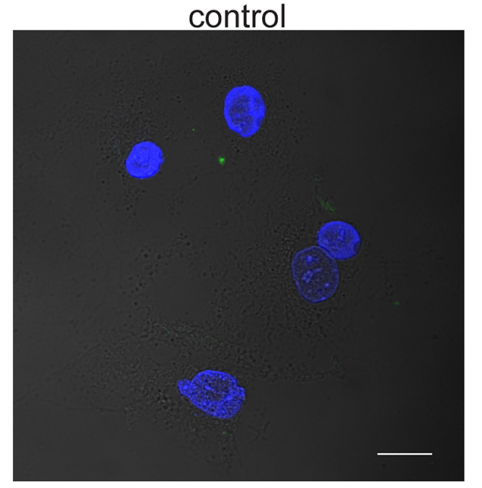

B

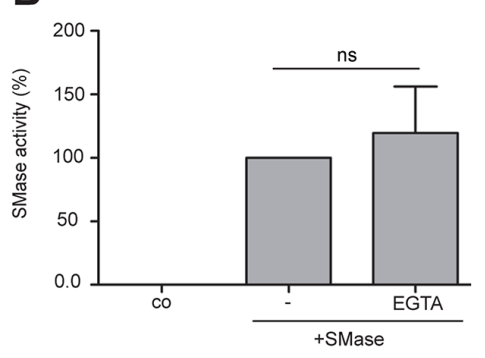

D

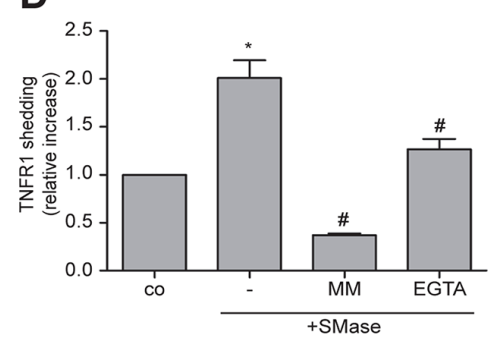

HUVEC

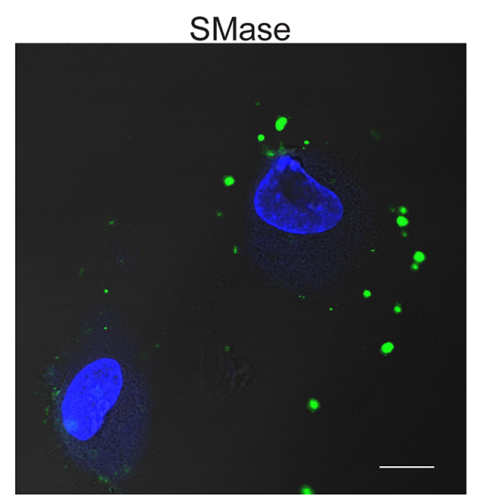

$\cos 7$

SMase

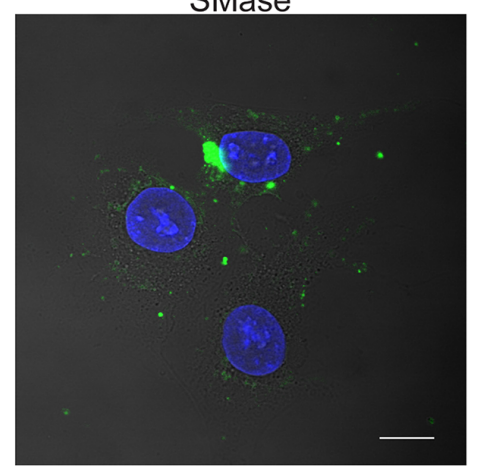

C

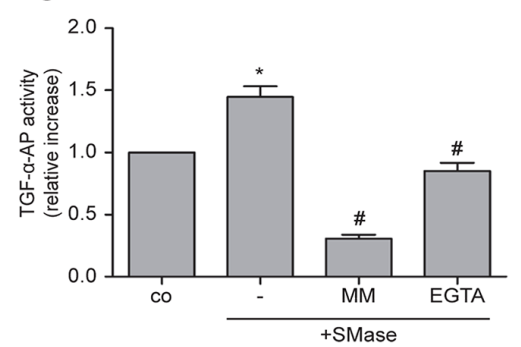

E

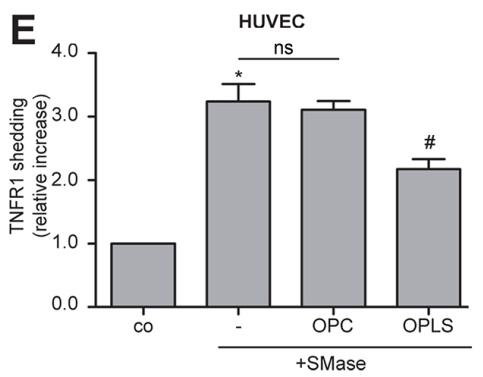

Figure 3: SMase-induced PS externalization and ADAM17 activation is $\mathbf{C a}^{\mathbf{2 +}}$-dependent. (A) HUVEC and COS7 cells were treated with $0.1 \mathrm{U} / \mathrm{ml}$ SMase in the presence and absence of the $\mathrm{Ca}^{2+}$-chelator EGTA $(10 \mathrm{mM})$ for 120 or 180 min, respectively. Thereafter, cells were stained with Annexin V-FITC for detection of externalized PS (green) and DAPI for visualizing the nucleus (blue). (B) EGTA did not affect SMase activity. The effect of EGTA $(10 \mathrm{mM})$ was controlled in a SMase activity assay. (C, D) SMase-induced ADAM17mediated shedding was analyzed in COS7 cells and HUVECs as stated in Figure 1 in the presence or absence of the metalloprotease inhibitor marimastat $(\mathrm{MM}, 10 \mu \mathrm{M})$ or the $\mathrm{Ca}^{2+}$-chelator EGTA $(10 \mathrm{mM})$. (E) SMase-induced TNFR1 shedding was significantly reduced by addition of the competing phosphatidylserine head group (OPLS) but not by the head group of PC (OPC). * indicates a significant increase compared to control, \# indicates a significant reduction in comparison to the stimulated sample, ns: no significant differences $(* \#: \mathrm{p}<0.05$; $\mathrm{n}=5 ; \pm \mathrm{SEM})$. 


\section{A}

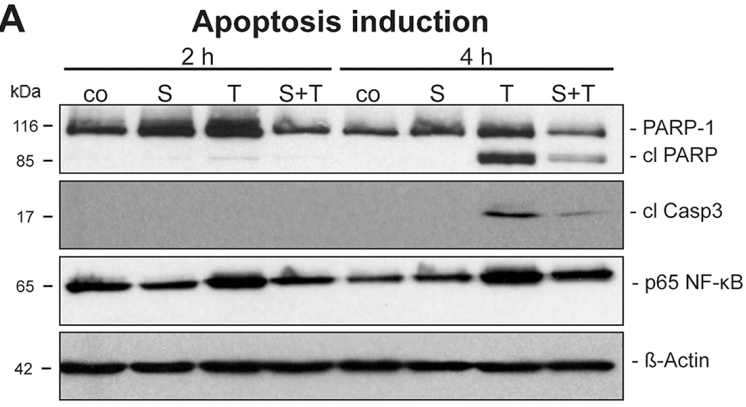

B DNA fragmentation
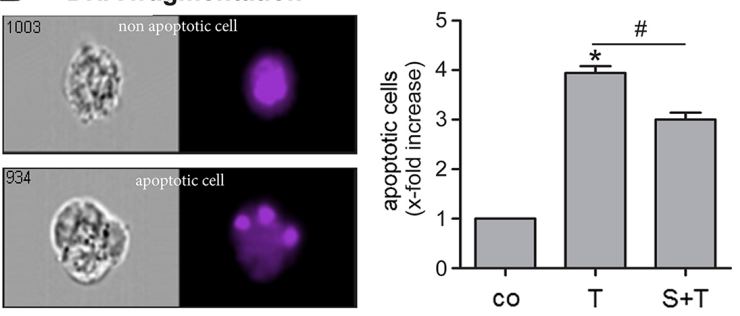

C

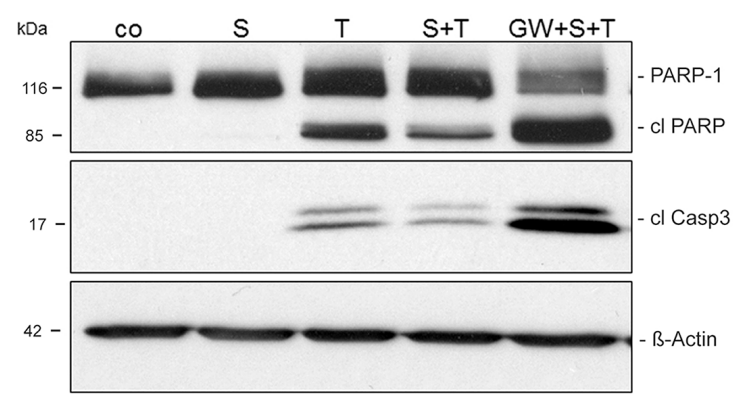

D

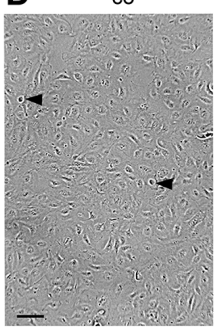

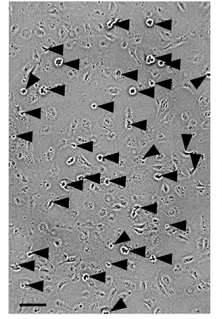

$\mathrm{S}+\mathrm{T}$

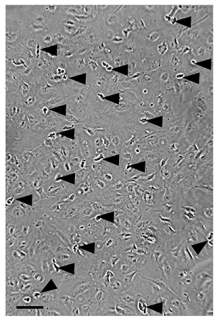

$\mathrm{GW}+\mathrm{S}+\mathrm{T}$

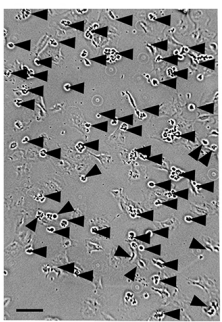

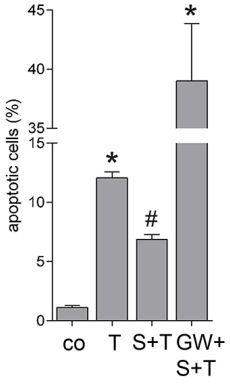

Figure 4: SMase treatment reduces the TNF- $\alpha$ sensitivity of endothelial cells. (A) HUVECs were pretreated with SMase (S, $0.1 \mathrm{U} / \mathrm{ml}, 2 \mathrm{~h})$ and stimulated with TNF- $\alpha(\mathrm{T}, 40 \mathrm{ng} / \mathrm{ml}+\mathrm{CHX}(5 \mu \mathrm{g} / \mathrm{ml})$ for 2 or $4 \mathrm{~h}$, followed by lysis and Western blot analyses. Shown are representative Western blots for total PARP-1, cleaved PARP (cl PARP), cleaved caspase-3 (cl Casp3), and phosphorylated p65 NF$\kappa \mathrm{B} . \beta$-Actin served as a loading control. (B) Apoptosis was additionally measured by quantifying nuclear fragmentation by ImageStream analysis. HUVECs were analyzed after overnight incubation with TNF- $\alpha / \mathrm{CHX}$ with or without SMase pretreatment as described. The means of three different independent experiments are shown. * indicates a significant increase compared to control, \# indicates a significant reduction in comparison to the stimulated sample $(* \#: \mathrm{p}<0.05)$. Data are represented as mean $\pm \mathrm{SEM}$. (C, D) TNF- $\alpha$-induced cell death is reduced upon SMase pre-treatment and reinforced upon ADAM17 inhibition. HUVECs were pretreated with SMase (SM, $0.1 \mathrm{U} / \mathrm{ml}, 2 \mathrm{~h})$ in the presence or absence of the inhibitor GW $(3 \mu \mathrm{M})$ and stimulated with TNF- $\alpha(\mathrm{T}, 40 \mathrm{ng} / \mathrm{ml})+\mathrm{CHX}(5 \mu \mathrm{g} / \mathrm{ml})$ for $4 \mathrm{~h}$. (C) Cells were analyzed by Western blotting. Shown is a representative blot $(n=4)$ for cleaved PARP-1 (cl PARP), and cleaved caspase-3 (cl Casp3), $\beta$-Actin served as a loading control. (D) The number of HUVECs showing TNF- $\alpha$-induced cell membrane blebbing is reduced upon SMase pre-treatment and reinforced upon ADAM17 inhibition. Cells were stimulated as described above and photographs were taken. Scale bars, $50 \mu \mathrm{m}$. The percentage of cells was determined by counting blebbing cells compared to the number of total cells on 3 randomly selected fields. * indicates a significant increase compared to control, \# indicates a significant reduction in comparison to the TNF- $\alpha$-stimulated sample (*\#: $\mathrm{p}<0.05 ; \mathrm{n}=6 ; \pm \mathrm{SEM}$; one-way ANOVA with post-hoc Tukey test). 
member of this family, assumes vitally important functions through liberation of biologically active substrates from cell surfaces. ADAM17 sheddase function is induced by a wide variety of agents [23]. A long-standing enigma relates to how signals generated along different pathways within the cell can be relayed to one and the same protease that is oriented at the cell surface. Recently, we presented evidence that PS exposure was the solution to this problem. Classical ADAM17 activation pathways were all found to provoke transient PS-translocation to the outer membrane leaflet. A cationic motif was identified in the membrane-proximal domain of ADAM17 that specifically interacted with phosphorylserine. Evidence was obtained that through this interaction, the protease would be attracted, enabling the catalytic domain to find its substrate. The model at the same time provided a simple explanation for the known fact that shedding of ADAM17 substrates accompanies apoptosis [18].

Although it is well known that SMase activity is elevated in the serum of patients suffering from several diseases [7], it is not clear where and how secreted SMase is active. This makes it impossible to compare the activities of exogenously applied SMase in cell culture experiments to endogenously secreted SMase in serum. Here, we used SMase concentrations of $0.1 \mathrm{U} / \mathrm{ml}$. This concentration is in the range of SMase activity shown to induce ceramiderich membrane regions in Molt-4 cells without inducing apoptosis [37], below the concentration that induces shedding of L-Selectin in granulocytes [31] and in the range of SMase activity shown to modify LDL particle in vitro [38]. It would be of interest to evaluate the role of endogenous SMase that is secreted upon stimulation with inflammatory mediators (TNF- $\alpha$, Interferon-gamma) [6] for ADAM17 activation in the future.

Here, we took the lead provided by work on erythrocytes and platelets and examined the effects of exogenously applied SMase treatment on PS exposure in nucleated cells. As expected from the literature, COS7 and HUVECs withstood treatment with the enzyme without loss of viability, confirming that ceramide itself is not cytotoxic. But its generation did produce dramatic effects on membrane architecture. PS exposure became evident after $30 \mathrm{~min}$ exposure of cells to soluble SMase and increased steadily thereafter. PS exposure was temporally linked to upregulation of ADAM17 function. This was shown with the use of two established model systems: first, the cleavage of AP-tagged TGF- $\alpha$ in transfected COS7 cells and second, the release of endogenous TNFR1 from HUVECs. Both models yielded the same results and, through employment of the previous strategy, PS externalization could be linked to enhanced substrate shedding. Thus, shedding was significantly inhibited in the presence of competing, soluble phosphorylserine, but not by phosphorylcholine, in the face of unaltered cell-surface expression of ADAM17. The asymmetric distribution of phospholipids is mediated by various transporters: PS and PE passively translocating to the external leaflet are normally returned to the inner leaflet through the action of ATP-dependent "flippases".

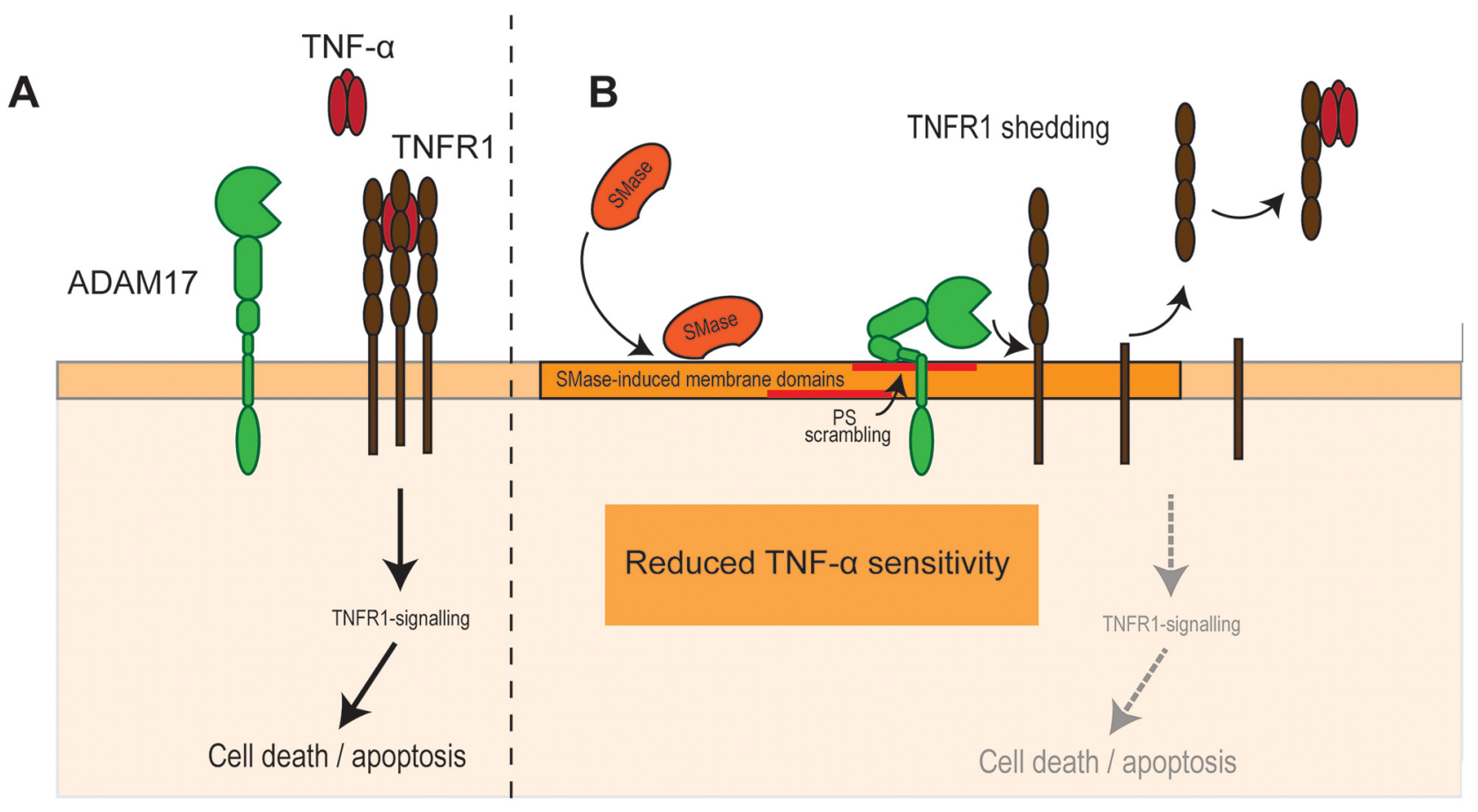

Figure 5: SMase activity impairs TNF- $\alpha$-induced cell death in endothelial cells. (A) TNF- $\alpha$ is a major trigger of endothelial apoptosis. (B) SMase activity leads to cell membrane changes and PS externalization from the inner to the outer cell membrane leaflet. PSinteraction enables ADAM17 to release its substrate TNFR1 thus impairing TNF- $\alpha$-induced cell death. 
Upon activation, scramblases non-specifically and bidirectionally translocate phospholipids between the outer and inner leaflets of the plasma membrane [39]. Function of the recently identified scramblase Anoctamin-6 depends on calcium $[29,40]$. This will most likely be the case for other scramblases as well. Thus, the finding that EGTA suppressed both PS externalization and TNFR1-release provided another line of support for our assumption.

In the context of cell death or survival, the net effect of ADAM17 sheddase activation may be expected to vary dependent on cell types with their respective expression of shed death ligands, death receptors and growth factors. Exploratory experiments were performed with endothelial cells for two reasons. First, TNF- $\alpha$-mediated endothelial cell death is a phenomenon of widespread importance. The inflammatory cytokine is involved in the development of atherosclerosis, reperfusion injury, hypertrophy and heart failure [41]. Second, among the shed ADAM17 substrates in endothelial cells, TNFR1 predominates over TNF- $\alpha$ and growth factors, which facilitates interpretation of the experimental outcome. A clear protective effect was observed. Thus, shedding of TNFR1 effected by pretreatment with sphingomyelinase blunted subsequent TNF- $\alpha$-induced apoptosis. This was reflected by a marked reduction in cleaved caspase- 3 and cleaved PARP a few hours after TNF- $\alpha$ treatment. The protective effect of SMase was reflected in conspicuous reduction of nuclear fragmentation. Incubation with the inhibitor GW abrogated these effects, providing a clear link between SMase and ADAM17 activation. The results tie in with the general concept that cleaved TNFR1 can bind away and thus protect neighboring cells from the action of TNF- $\alpha$ [42-45]. GW treatment appeared to even exacerbate cell death, highlighting the vital importance of ADAM17. The additional effect might be due to several factors. ADAM17 displays constitutive activity; this might cause protective effects to accumulate over time. These would be inhibited by GW. Moreover, TNF- $\alpha$ induces reportedly the release of endogenous SMase in endothelial cells [6], that might act in addition to the extracellularly applied enzyme. In this context, the evaluation of the role of endogenous SMase on ADAM17-mediated TNFR1 shedding becomes of high interest. Moreover, TNF- $\alpha$ is known to induce several chemokines and adhesion molecules in endothelial cells and this may also have proatherogenic effects. The question would follow whether these inflammatory responses would be modified by GW, ADAM17 knockdown or by targeting endogenous SMase. It would be of high interest to address such questions in future studies.

Based on our data presented here, we propose the following model (Figure 5). SMase activity leads to cell membrane changes and PS externalization from the inner to the outer cell membrane leaflet. In endothelial cells, PS-interaction enables ADAM17 to release its substrate TNFR1 thus impairing TNF- $\alpha$-induced apoptosis. In other cell types, different consequences might follow.
In conjunction with previous investigations, a possible circle of events now lends itself to speculation regarding the possible significance of ceramide generation in apoptosis. Existing evidence indicates that breakdown of phospholipid asymmetry during induced apoptosis can entail not only the translocation of PS to the outer membrane leaflet, but also a concomitant movement of sphingomyelin to the inner leaflet, where the molecule is cleaved by nSMase. The ceramide thus generated was not directly involved in the death cascade, but was instrumental in promoting membrane re-organization and blebbing [10]. Two aspects may now be added to the scenario. First, generation of ceramide will itself promote breakdown of phospholipid asymmetry, and a self-perpetuating circle of events may thus arise. Second, ADAM17 upregulation by externalized PS may serve a protective function. In endothelial cells, this may be effected mainly be the release of decoy TNFR1. In others, liberation of membrane-anchored growth factors, in particular EGFR-ligands, may play relevant roles.

In addition, several other aspects should be considered: Pore-forming bacterial toxins perturb membrane organization and this has been shown to promote ceramide formation via nSMase, which in turn leads to ADAM17 activation [14, 31]. Deficiency of nSMase activity blunts the capacity of $S$. aureus to invoke pulmonary damage, which is dependent on cleavage of syndecan1 by ADAM17 [46, 47].

Taken together, our results demonstrate a hitherto undescribed link between sphingomyelinase activity and ADAM17 function arising from breakdown of phospholipid asymmetry. Depending on the cell type and the substrates, SMase-induced ADAM17 activation may lead to multifaceted functional consequences. Our data on endothelial cells clearly support the view that ADAM17mediated TNFR1 shedding counteracts TNF- $\alpha$-induced cell death. Overall, many other connections between ceramide formation and the ADAM-regulatory network are likely to be uncovered through directed searches in the foreseeable future.

\section{MATERIALS AND METHODS}

\section{Reagents}

Sphingomyelinase from Staphylococcus aureus, Annexin V-FITC, cycloheximide (CHX), O-phosphoL-serine (OPLS), phosphorylcholine (OPC), phorbol 12-myristate-13-acetate (PMA), and EGTA (ethylene glycol tetraacetic acid) were obtained from Sigma. OPLS and OPC were dissolved in $\mathrm{H}_{2} \mathrm{O}$ and adjusted to $\mathrm{pH} 7$ before use. Hydroxamate-based ADAM17/10 inhibitor GW280264 [24] was purchased from Aeobious. Marimastat and ADAM10 inhibitor GI254023X [24] were obtained from Tocris Bioscience. Highly purified human recombinant TNF- $\alpha$ was provided by BASF Bioresearch. 


\section{Cell culture}

COS7 cells (ATCC) were grown in high glucose Dulbecco's Modified Eagle Medium (DMEM) supplemented with $10 \%(\mathrm{v} / \mathrm{v})$ heat inactivated fetal calf serum, $100 \mathrm{U} / \mathrm{ml}$ penicillin, and $100 \mu \mathrm{g} / \mathrm{ml}$ streptomycin $(\mathrm{P} / \mathrm{S})$. Human umbilical vein endothelial cells (HUVECs) from multiple donors were purchased from PromoCell and grown in endothelial cell growth medium (PromoCell) and $1 \% \mathrm{P} / \mathrm{S}$. Passages between two and eight were used for experiments.

\section{Transfection and TGF- $\alpha-A P$ shedding assay}

The plasmid for alkaline phosphatase tagged TGF- $\alpha$ expression was from Carl Blobel (Hospital for Special Surgery, New York, USA). COS7 cells were transfected with Turbofect Transfection Reagent (Thermo Fisher Scientific) according to the manufacturer's instructions. $24 \mathrm{~h}$ after transfection medium was replaced by fresh DMEM and pre-incubated for $1 \mathrm{~h}$ before stimulation with sphingomyelinase. Supernatants and cell lysates (lysed in $2.5 \%(\mathrm{v} / \mathrm{v})$ Triton- $\mathrm{X}$ in $\mathrm{H}_{2} \mathrm{O}$ with $1 \mathrm{mM}$ EDTA and $10 \mathrm{mM}$ 1,10-phenantroline) were collected and the APactivity was determined by employing the AP-substrate 4-nitrophenyl phosphate (Sigma Aldrich, $1 \mathrm{mg} / \mathrm{ml}$ ). For shedding analyses, the relative AP-activity of supernatant compared to the total AP-activity of supernatant plus cell lysates normalized to the unstimulated control is shown.

\section{TNFR1 enzyme linked immunosorbent assay}

TNFR1 ELISA was obtained from R\&D Systems and performed according to manufacturer's instructions. HUVECs were grown to $90 \%$ confluence in 12-well plates in endothelial growth medium. Before stimulation, medium was changed to endothelial basal medium and pre-incubation with or without the corresponding inhibitors took place for 15 to $30 \mathrm{~min}$. Thereafter, $0.1 \mathrm{U} /$ $\mathrm{ml}$ sphingomyelinase was added for $2 \mathrm{~h}$. The resulting supernatants were cleared by centrifugation and stored at $-20^{\circ} \mathrm{C}$ until the ELISA were performed.

\section{Annexin V-FITC staining}

Cells were grown on coverslips (collagenated for HUVECs) to semi-confluence. After the indicated stimulation/inhibition periods the coverslips were incubated with a 1:20 solution of Annexin V-FITC in Annexin-Binding-Buffer (ABB; $10 \mathrm{mM}$ HEPES, $140 \mathrm{mM} \mathrm{NaCl}, 2.5 \mathrm{mM} \mathrm{CaCl}_{2}, \mathrm{pH} 7.4$ ) for $5 \mathrm{~min}$ in the dark at room temperature. The coverslips were carefully washed twice with $\mathrm{ABB}$ and fixed with 3\%(v/v) paraformaldehyde for $15 \mathrm{~min}$. Then, the coverslips were washed six times with PBS, once with distilled water and mounted in Mowiol embedding medium containing DABCO and DAPI.

\section{Immunoblot analysis}

For analysing TNF- $\alpha$-induced cell signaling, cells were lysed at $4^{\circ} \mathrm{C}$ in TNE buffer $(50 \mathrm{mM}$ Tris, $\mathrm{pH} 8.0$; $1 \%(\mathrm{v} / \mathrm{v}) \mathrm{NP}-40,150 \mathrm{mM} \mathrm{NaCl}, 3 \mathrm{mM}$ EDTA, $1 \mathrm{mM}$ sodium orthovanadate, $5 \mathrm{mM}$ sodium fluoride, $20 \mu \mathrm{M}$ z-VAD-FMK, and cOmplete inhibitor cocktail (Roche)). Identical amounts of protein per lane were resolved by electrophoresis on SDS-polyacrylamide gels and transferred onto nitrocellulose membranes by Western blotting. Proteins were detected by using antibodies specific for p65 NF- $\mathrm{kB}$ (Cell Signaling, catalogue number 3033S), PARP-1 (Cell Signaling, catalogue number 9542), cleaved caspase-3 (Cell Signaling, catalogue number 9661 $\mathrm{L} / \mathrm{S}$ ) and were stained with the corresponding peroxidasecoupled secondary antibody (Jackson ImmunoResearch, catalogue number 111-035-146 and 111-035-146) and the LumiGLO chemiluminescent substrate (Cell Signaling, Danvers, MA) and captured on Amersham Hyperfilm ECL (GE Healthcare, Munich, Germany).

For analysing ADAM17 expression, cells were washed once with PBS and lysed in lysis buffer $(5 \mathrm{mM}$ Tris-HCl pH 7.5, 1 mM EGTA, $250 \mathrm{mM}$ saccharose and $1 \%(\mathrm{v} / \mathrm{v})$ Triton X-100) supplemented with cOmplete inhibitor cocktail (Roche Applied Science) and 10 $\mathrm{mM}$ 1,10-phenantroline. Equal amounts of protein were loaded on $10 \%$ SDS-PAGE gels. The samples were electrotransferred onto polyvinylidene difluoride membranes (Hybond-P; Amersham) and blocked for 1 $\mathrm{h}$ with $5 \%$ skim milk in Tris-buffered saline containing $0.1 \%$ Tween-20 (TBST). After $1 \mathrm{~h}$ incubation with the anti-ADAM17 antibody (Chemicon AB19027, 1:2000) in TBST, the membranes were washed three times in TBST. The primary antibody was detected using affinity-purified peroxidase (POD)-conjugated secondary antibodies (1:10000) for $1 \mathrm{~h}$ at room temperature. Detection was carried out using the ECL detection system (Amersham). Signals were recorded by a luminescent image analyzer (Fusion FX7 imaging system; PEQLAB Biotechnologie). Equal loading as well as efficiency of transfer were routinely verified for all Western blots by reprobing the membranes for Actin or Tubulin (Sigma, catalogue number A1978; DSHB clone E7).

\section{Sphingomyelinase activity assay}

The fluorometric sphingomyelinase activity assay (Cayman Chemicals, no. 10006964) was used to analyze the relative SMase activity. In brief, $0.1 \mathrm{U} / \mathrm{ml}$ bacterial SMase was added to endothelial basal medium with or without $10 \mathrm{mM}$ EGTA and the SMase activity was determined according to manufacturer's instructions.

\section{Image acquisition and processing}

Image acquisition of Annexin V-FITC stained cells was performed with an inverted confocal microscope 
(Fluoview FV1000, Olympus) using a UPLSAPO 60 oil-immersion objective (numerical aperture: 1.35) and 2x zoom. Annexin V-FITC was excited at $488 \mathrm{~nm}$ and emission was recorded at $520 \mathrm{~nm}$. Images were acquired with the same laser and detection settings for each experimental setup. Phase contrast images for quantification of blebbing cells were taken with a Canon DS126291 camera and a Hund Wetzlar Wllovert30 microscope. Calculation was performed by counting blebbing cells in 3 random microscope fields of six cover slips from independent experiments, respectively, and expressing these counts as a proportion of total cells in identical fields.

\section{Imagestream apoptosis assays}

The percentage of cells with fragmented DNA was measured with the ImageStream (Amnis/EMD Millipore) system as described in [48]. For that, two $10 \mathrm{~cm}$ tissue flasks per sample of semiconfluent HUVECs were stimulated as indicated, detached with Accutase ${ }^{\circledR}$ (Thermo Fisher Scientific), washed in PBS with 2 mM EDTA and stained with Hoechst (dilution 1:10.000) for 30 min on ice. The apoptosis wizard plug-in was used for assaying the number of cells showing nuclear fragmentation compared to cells with intact nuclei.

\section{Statistical analysis}

If not otherwise indicated, One-Way ANOVA and subsequent Bonferroni post-tests were performed.

\section{Abbreviations}

ADAM, a disintegrin and metalloprotease; ANO6, Anoctamin-6; AP, alkaline-phosphatase; aSMase, acid sphingomyelinase; ATP, adenosine triphosphate; CHX, cycloheximide; EGFR, epithelial growth factor receptor; HB-EGF, heparin binding-epithelial growth factor; HUVECs, human umbilical vein endothelial cells; NF$\mathrm{kB}$, nuclear factor kappa-light-chain-enhancer of activated B cells; nSMase, neutral sphingomyelinase; OPC, phosphorylcholine; OPLS, O-phospho-L-serine; PARP-1, poly[ADP-Ribose] polymerase 1; PS, phosphatidylserine; PMA, phorbol 12-myristate 13-acetate; SMase, sphingomyelinase; TGF- $\alpha$, transforming growth factoralpha; TMEM16F, transmembrane protein $16 \mathrm{~F}$; TNF- $\alpha$, tumor necrosis factor-alpha; TNFR1, tumor necrosis factor-alpha receptor 1 .

\section{Author contributions}

K.R. conceived the project. K.R., S.B., M.S. and A.S. designed the experiments; A.S., M.D., L.B., J.B. and F.K., performed the biological and biochemical experiments and analyzed the data. J.F. performed the ImageStream analysis, J.F.C. the TNF- $\alpha$ signaling immunoblot analysis, and D.A. and S.S. analyzed the data. The manuscript was written by K.R. and S.B. with contributions from all authors.

\section{ACKNOWLEDGMENTS}

This work was supported by the Deutsche Forschungsgemeinschaft, CRC877 (K.R. (A4), S.S. (B1), D.A. (B2), the RTG1743 (F.K. and L.B.) and the Cluster of Excellence 'Inflammation at Interfaces'. The microscope platform was kindly provided by the CRC877 project Z3.

\section{CONFLICTS OF INTEREST}

The authors declare no competing financial interests.

\section{REFERENCES}

1. Hannun YA. Functions of ceramide in coordinating cellular responses to stress. Science 1996; 274:1855-1859.

2. Gulbins E, Li PL. Physiological and pathophysiological aspects of ceramide. Am J Physiol Regul Integr Comp Physiol. 2006; 290:R11-R26.

3. Kitatani K, Idkowiak-Baldys J, Hannun YA. The sphingolipid salvage pathway in ceramide metabolism and signaling. Cell Signal. 2008; 20:1010-1018.

4. Lang E, Bissinger R, Gulbins E, Lang F. Ceramide in the regulation of eryptosis, the suicidal erythrocyte death. Apoptosis. 2015; 20:758-767.

5. Milhas D, Clarke CJ, Hannun YA. Sphingomyelin metabolism at the plasma membrane: implications for bioactive sphingolipids. FEBS Lett. 2010; 584:1887-1894.

6. Marathe S, Schissel SL, Yellin MJ, Beatini N, Mintzer R, Williams KJ, Tabas I. Human vascular endothelial cells are a rich and regulatable source of secretory sphingomyelinase. Implications for early atherogenesis and ceramide-mediated cell signaling. J Biol Chem. 1998; 273:4081-4088.

7. Jenkins RW, Canals D, Hannun YA. Roles and regulation of secretory and lysosomal acid sphingomyelinase. Cell Signal. 2009; 21:836-846.

8. Tani M, Hannun YA. Analysis of membrane topology of neutral sphingomyelinase 2. FEBS Lett. 2007; 581:1323-1328.

9. Garcia-Ruiz C, Colell A, Mari M, Morales A, Calvo M, Enrich C, Fernandez-Checa JC. Defective TNF-alphamediated hepatocellular apoptosis and liver damage in acidic sphingomyelinase knockout mice. J Clin Invest. 2003; 111:197-208.

10. Tepper AD, Ruurs P, Wiedmer T, Sims PJ, Borst J, van Blitterswijk WJ. Sphingomyelin hydrolysis to ceramide during the execution phase of apoptosis results from phospholipid scrambling and alters cell-surface morphology. J Cell Biol. 2000; 150:155-164.

11. Luberto C, Hassler DF, Signorelli P, Okamoto Y, Sawai H, Boros E, Hazen-Martin DJ, Obeid LM, Hannun YA, Smith GK. Inhibition of tumor necrosis factor-induced cell death 
in MCF7 by a novel inhibitor of neutral sphingomyelinase. J Biol Chem. 2002; 277:41128-41139.

12. Lin T, Genestier L, Pinkoski MJ, Castro A, Nicholas S, Mogil R, Paris F, Fuks Z, Schuchman EH, Kolesnick RN, Green DR. Role of acidic sphingomyelinase in Fas/CD95mediated cell death. J Biol Chem. 2000; 275:8657-8663.

13. Paris F, Fuks Z, Kang A, Capodieci P, Juan G, Ehleiter D, Haimovitz-Friedman A, Cordon-Cardo C, Kolesnick R. Endothelial apoptosis as the primary lesion initiating intestinal radiation damage in mice. Science 2001; 293:293-297.

14. Walev I, Weller U, Strauch S, Foster T, Bhakdi S. Selective killing of human monocytes and cytokine release provoked by sphingomyelinase (beta-toxin) of Staphylococcus aureus. Infect Immun. 1996; 64:2974-2979.

15. Tajima A, Iwase T, Shinji H, Seki K, Mizunoe Y. Inhibition of endothelial interleukin-8 production and neutrophil transmigration by Staphylococcus aureus beta-hemolysin. Infect Immun. 2009; 77:327-334.

16. Abed M, Towhid ST, Mia S, Pakladok T, Alesutan I, Borst O, Gawaz M, Gulbins E, Lang F. Sphingomyelinaseinduced adhesion of eryptotic erythrocytes to endothelial cells. Am J Physiol Cell Physiol. 2012; 303:C991-C999.

17. Munzer P, Borst O, Walker B, Schmid E, Feijge MA, Cosemans JM, Chatterjee M, Schmidt EM, Schmidt S, Towhid ST, Leibrock C, Elvers M, Schaller M, et al. Acid sphingomyelinase regulates platelet cell membrane scrambling, secretion, and thrombus formation. Arterioscler Thromb Vasc Biol. 2014; 34:61-71.

18. Sommer A, Kordowski F, Buch J, Maretzky T, Evers A, Andra J, Dusterhoft S, Michalek M, Lorenzen I, Somasundaram P, Tholey A, Sonnichsen FD, Kunzelmann K, et al. Phosphatidylserine exposure is required for ADAM17 sheddase function. Nat Commun. 2016; 7:11523.

19. Sommer A, Bhakdi S, Reiss K. How membrane asymmetry regulates ADAM17 sheddase function. Cell Cycle. 2016; 15:2995-2996.

20. Reiss K, Saftig P. The "a disintegrin and metalloprotease" (ADAM) family of sheddases: physiological and cellular functions. Semin Cell Dev Biol. 2009; 20:126-137.

21. Reddy P, Slack JL, Davis R, Cerretti DP, Kozlosky CJ, Blanton RA, Shows D, Peschon JJ, Black RA. Functional analysis of the domain structure of tumor necrosis factor-alpha converting enzyme. J Biol Chem. 2000; 275:14608-14614.

22. Bell JH, Herrera AH, Li Y, Walcheck B. Role of ADAM17 in the ectodomain shedding of TNF-alpha and its receptors by neutrophils and macrophages. J Leukoc Biol. 2007; 82:173-176.

23. Le Gall SM, Bobe P, Reiss K, Horiuchi K, Niu XD, Lundell D, Gibb DR, Conrad D, Saftig P, Blobel CP. ADAMs 10 and 17 represent differentially regulated components of a general shedding machinery for membrane proteins such as transforming growth factor alpha, L-selectin, and tumor necrosis factor alpha. Mol Biol Cell. 2009; 20:1785-1794.

24. Ludwig A, Hundhausen C, Lambert MH, Broadway N, Andrews RC, Bickett DM, Leesnitzer MA, Becherer JD. Metalloproteinase inhibitors for the disintegrinlike metalloproteinases ADAM10 and ADAM17 that differentially block constitutive and phorbol ester-inducible shedding of cell surface molecules. Comb Chem High Throughput Screen. 2005; 8:161-171.

25. Srour N, Lebel A, McMahon S, Fournier I, Fugere M, Day $\mathrm{R}$, Dubois CM. TACE/ADAM-17 maturation and activation of sheddase activity require proprotein convertase activity. FEBS Lett. 2003; 554:275-283.

26. Lang F, Gulbins E, Lerche H, Huber SM, Kempe DS, Foller M. Eryptosis, a window to systemic disease. Cell Physiol Biochem. 2008; 22:373-380.

27. Nagata S, Suzuki J, Segawa K, Fujii T. Exposure of phosphatidylserine on the cell surface. Cell Death Differ. 2016; 23:952-961.

28. Segawa K, Kurata S, Nagata S. Human type IV P-type ATPases that work as plasma membrane phospholipid flippases and their regulation by caspase and calcium. J Biol Chem. 2016; 291:762-772.

29. Suzuki J, Umeda M, Sims PJ, Nagata S. Calcium-dependent phospholipid scrambling by TMEM16F. Nature 2010; 468:834-838.

30. Yang H, Kim A, David T, Palmer D, Jin T, Tien J, Huang F, Cheng T, Coughlin SR, Jan YN, Jan LY. TMEM16F forms a $\mathrm{Ca} 2+$-activated cation channel required for lipid scrambling in platelets during blood coagulation. Cell. 2012; 151:111-122.

31. Walev I, Tappe D, Gulbins E, Bhakdi S. Streptolysin O-permeabilized granulocytes shed L-selectin concomitantly with ceramide generation via neutral sphingomyelinase. J Leukoc Biol. 2000; 68:865-872.

32. Holopainen JM, Subramanian M, Kinnunen PK. Sphingomyelinase induces lipid microdomain formation in a fluid phosphatidylcholine/sphingomyelin membrane. Biochemistry 1998; 37:17562-17570.

33. Grassme H, Jekle A, Riehle A, Schwarz H, Berger J, Sandhoff K, Kolesnick R, Gulbins E. CD95 signaling via ceramide-rich membrane rafts. J Biol Chem. 2001; 276:20589-20596.

34. Kolesnick RN, Goni FM, Alonso A. Compartmentalization of ceramide signaling: physical foundations and biological effects. J Cell Physiol.2000; 184:285-300.

35. Bianco F, Perrotta C, Novellino L, Francolini M, Riganti L, Menna E, Saglietti L, Schuchman EH, Furlan R, Clementi E, Matteoli M, Verderio C. Acid sphingomyelinase activity triggers microparticle release from glial cells. EMBO J. 2009; 28:1043-1054.

36. Turola E, Furlan R, Bianco F, Matteoli M, Verderio C. Microglial microvesicle secretion and intercellular signaling. Front Physiol. 2012; 3:149. 
37. Zhang P, Liu B, Jenkins GM, Hannun YA, Obeid LM. Expression of neutral sphingomyelinase identifies a distinct pool of sphingomyelin involved in apoptosis. J Biol Chem. 1997; 272:9609-9612.

38. Xu XX, Tabas I. Sphingomyelinase enhances low density lipoprotein uptake and ability to induce cholesteryl ester accumulation in macrophages. J Biol Chem. 1991; 266:24849-24858.

39. Kodigepalli KM, Bowers K, Sharp A, Nanjundan M. Roles and regulation of phospholipid scramblases. FEBS Lett. 2015; 589:3-14.

40. Banerjee J, Leung CT, Li A, Peterson-Yantorno K, Ouyang H, Stamer WD, Civan MM. Regulatory roles of anoctamin-6 in human trabecular meshwork cells. Invest Ophthalmol Vis Sci. 2017; 58:492-501.

41. Kleinbongard P, Heusch G, Schulz R. TNFalpha in atherosclerosis, myocardial ischemia/reperfusion and heart failure. Pharmacol Ther. 2010; 127:295-314.

42. Deng M, Loughran PA, Zhang L, Scott MJ, Billiar TR. Shedding of the tumor necrosis factor (TNF) receptor from the surface of hepatocytes during sepsis limits inflammation through cGMP signaling. Sci Signal. 2015; 8:ra11.

43. Murthy A, Defamie V, Smookler DS, Di Grappa MA, Horiuchi K, Federici M, Sibilia M, Blobel CP, Khokha R.
Ectodomain shedding of EGFR ligands and TNFR1 dictates hepatocyte apoptosis during fulminant hepatitis in mice. $\mathrm{J}$ Clin Invest. 2010; 120:2731-2744.

44. Terrado J, Monnier D, Perrelet D, Vesin D, Jemelin S, Buurman WA, Mattenberger L, King B, Kato AC, Garcia I. Soluble TNF receptors partially protect injured motoneurons in the postnatal CNS. Eur J Neurosci. 2000; 12:3443-3447.

45. Xia M, Xue SB, Xu CS. Shedding of TNFR1 in regenerative liver can be induced with TNF alpha and PMA. World J Gastroenterol. 2002; 8:1129-1133.

46. Hayashida A, Bartlett AH, Foster TJ, Park PW. Staphylococcus aureus beta-toxin induces lung injury through syndecan-1. Am J Pathol. 2009; 174:509-518.

47. Pruessmeyer J, Martin C, Hess FM, Schwarz N, Schmidt S, Kogel T, Hoettecke N, Schmidt B, Sechi A, Uhlig S, Ludwig A. A disintegrin and metalloproteinase 17 (ADAM17) mediates inflammation-induced shedding of syndecan-1 and -4 by lung epithelial cells. J Biol Chem. 2010; 285:555-564.

48. Fritsch J, Fickers R, Klawitter J, Sarchen V, Zingler P, Adam D, Janssen O, Krause E, Schutze S. TNF induced cleavage of HSP90 by cathepsin D potentiates apoptotic cell death. Oncotarget. 2016; 7:75774-75789. https://doi. org/10.18632/oncotarget.12411. 